\title{
Anticancer effects of bifidobacteria on colon cancer cell lines
}

\author{
Zeinab Faghfoori ${ }^{1}$, Mohammad Hasan Faghfoori ${ }^{2}$, Amir Saber ${ }^{3,7^{*}} \mathbb{D}$, Azimeh Izadi $^{4}$ and \\ Ahmad Yari Khosroushahi ${ }^{5,6}$
}

\begin{abstract}
Background: Colorectal cancer (CRC), with a growing incidence trend worldwide, is resistant to apoptosis and has uncontrolled proliferation. It is recently reported that probiotic microorganisms exert anticancer effects. The genus Bifidobacterium, one of the dominant bacterial populations in the gastrointestinal tract, has received increasing attention because of widespread interest in using it as health-promoting microorganisms. Therefore, the present study aimed to assess the apoptotic effects of some bifidobacteria species on colon cancer cell lines.

Methods: The cytotoxicity evaluations performed using MTT assay and FACS-flow cytometry tests. Also, the effects of five species of bifidobacteria secretion metabolites on the expression level of anti- or pro-apoptotic genes including BAD, BCl-2, Caspase-3, Caspase-8, Caspase-9, and Fas-R studied by real-time polymerase chain reaction (RT-PCR) method.

Results: The cell-free supernatant of all studied bifidobacteria significantly decreased the survival rates of colon cancer cells compared with control groups. Flow cytometric and RT-PCR results indicated that apoptosis is induced by bifidobacteria secretion metabolites and the mechanism for the action of bifidobacteria species in CRC prevention could be down-regulation and up-regulation of anti-apoptotic and, pro-apoptotic genes.

Conclusions: In the present study, different bifidobacteria species showed anticancer activity on colorectal cancer cells through down-regulation and up-regulation of anti-apoptotic and pro-apoptotic genes. However, further studies are required to clarify the exact mechanism of apoptosis induction by bifidobacteria species.
\end{abstract}

Keywords: Colorectal cancer, Probiotic, Bifidobacteria, Apoptosis

\section{Introduction}

Cancer as a major public health problem has a growing incidence trend worldwide. It is estimated that the number of global cancer deaths rises $45 \%$ from 2007 to $2030[1,2]$. CRC, the most common malignancy of the gastrointestinal tract, is the third and second most common cancer in males and females, respectively, and is the fourth leading cause of cancer death worldwide [3, 4].

\footnotetext{
*Correspondence: amir.saber@kums.ac.ir

${ }^{7}$ Department of Nutritional Sciences, School of Nutritional Sciences and Food Technologies, Kermanshah University of Medical Sciences, Isar Sq., next to Farabi Hospital, P.O. Box 6719851351, Kermanshah, Iran Full list of author information is available at the end of the article
}

The number of new cases is increasing quickly due to the rising of different risk factors. The risk factors for CRC are including modifiable such as smoking, alcohol, physical inactivity, and obesity, and nonmodifiable factors like familial risk, male sex, older age, and race/ethnicity [5]. It has been indicated that the general population of intestinal bacteria and microbial dysbiosis may contribute to the initiation and the etiology of CRC [6] thus, any factor that could modify the gut microbiota may prevent the disease. Some studies proposed that the ingestion of certain microorganisms decreases both the risk of developing certain types of cancer and also tumor growth, so a lot of attention has been focused on probiotic yeasts and bacteria like lactobacilli and bifidobacteria [7-11].

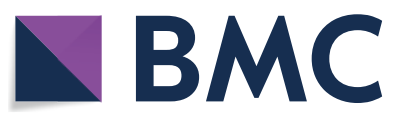

(c) The Author(s) 2021. This article is licensed under a Creative Commons Attribution 4.0 International License, which permits use, sharing, adaptation, distribution and reproduction in any medium or format, as long as you give appropriate credit to the original author(s) and the source, provide a link to the Creative Commons licence, and indicate if changes were made. The images or other third party material in this article are included in the article's Creative Commons licence, unless indicated otherwise in a credit line to the material. If material is not included in the article's Creative Commons licence and your intended use is not permitted by statutory regulation or exceeds the permitted use, you will need to obtain permission directly from the copyright holder. To view a copy of this licence, visit http://creativeco mmons.org/licenses/by/4.0/. The Creative Commons Public Domain Dedication waiver (http://creativecommons.org/publicdomain/ zero/1.0/) applies to the data made available in this article, unless otherwise stated in a credit line to the data. 
The genus Bifidobacterium contains approximately 57 (sub) species. They are among the dominant bacterial populations in the gastrointestinal tract and the normal inhabitants of a healthy human gut. To date, almost ten species/subspecies of Bifidobacterium have been detected in the human intestine. Among the bifidobacterial species, B. catenulatum, B. pseudocatenulatum, $B$. adolescentis, B. longum, B. breve, B. bifidum, B. animalis, and $B$. dentium are commonly found in the feces of healthy subjects $[12,13]$. Numerous studies indicated that changes in the number or/and composition of their populations are one of the most frequent situations that present in some diseases like inflammatory bowel disease, colorectal cancer, or irritable bowel syndrome [14]. During infancy, almost $80 \%$ of the gut microbiota consisted of bifidobacteria, and dysbiosis during infancy increases the risk of childhood diseases and could also affect the health of the host in the future [15].

In the last 15 years, the genus Bifidobacterium has received increasing attention due to widespread interest in using as health-promoting microorganisms, i.e., known as probiotics, in the food industry, and many products containing bifidobacteria such as fermented milk, yogurt, and healthy foods that produced for the microbiota modification $[16,17]$.

Some species of bifidobacteria are able to decrease carcinogen-induced DNA damage, pre-neoplastic lesions, and tumors in the colon of rats $[18,19]$. Administration of 3 bacteria including Lactobacillus acidophilus, B. bifidum, and B. infantum altered the gut microbiota and decreased colon cancer development by decreasing tumor incidence, multiplicity/count, and volume [7]. Moreover, a recent study investigated the effects of Bifidobacterium. Breve, Lactobacillus. reuteri and a cocktail of 10 strains from Lactobacillus and Bifidobacterium on LS174T (human colon adenocarcinoma cell line) and CRC mice model. In this study, treatment with Bifidobacteria showed the most apoptosis-inducing effects on LS174T cells in comparison to other bacterial treatments. Besides, the incidence of tumors and their size was significantly lower and smaller in Bifidobacteria treated mice in comparison to untreated CRC mice [20]. In another study, the anticancer effect of $B$. adolescentis SPM0212 extract, isolated from fecal samples of healthy peoples, was studied on human colon cancer cell lines (Caco-2, HT-29, and SW480) and the results showed that its extract significantly inhibits the proliferation of both cell lines [21].

The exact mechanisms responsible for the anti-cancer activity of these organisms are unknown yet, but some proposed mechanisms may influence metabolic, immunological, and protective functions within the colon, and also they may stimulate tumor cell apoptosis [22].
Apoptosis is an active cellular process that damaged or mutant cells undergo self-destruction and can help the organism for control normal development. Each step of apoptosis requires many proteins such as caspases that block tumor progression [23]. However, the exact molecular pathways by which bifidobacteria affect tumor cells remains unclear. Therefore, the present study aimed to assess the anticancer effects of some bifidobacteria species on HT-29 and Caco-2 cell lines in comparison to normal epithelial cells $(\mathrm{KDR} / 293)$ by focusing on the main apoptosis pathways.

\section{Materials and methods}

\section{Cell-free supernatant preparation}

Five species of bifidobacteria including $B$. adolescentis (ATCC 15703, PTCC1536), B. animalis subsp. lactis (PTCC1736), B. animalis subsp. animalis (ATCC 25527, PTCC 1631), B. bifidum (ATCC 29521, PTCC 1644), and B. angulatum (ATCC 27535, PTCC 1366) were obtained from the Persian Type Culture Collection (PTCC) from the Iranian Research Organization for Science and Technology (IROST). Bifidobacteria strains were cultured in de Man-Rogosa agar (MRS) (Merck, Darmstadt, Germany) at $37{ }^{\circ} \mathrm{C}$ for $72 \mathrm{~h}$ in an anaerobic incubator. Then, the cultures were centrifuged at $4500 \mathrm{rpm}$ for $15 \mathrm{~min}$ at $4{ }^{\circ} \mathrm{C}$. Fifty $\mathrm{mL}$ of each supernatant mixed with $75 \mathrm{~mL}$ volume of methanol and gently agitated for $24 \mathrm{~h}$. The methanolic extracts were dried by lyophilization and obtained dried materials were dissolved in different amounts (5-30 $\mathrm{mg} / \mathrm{mL})$ in each used cell culture including Dulbecco Modified Eagle medium (DMEM) (Gibco, Grand Island, NY, USA), and Roswell Park Memorial Institute medium (RPMI) 1640 (Sigma, St Louis, MO, USA). Finally, the $\mathrm{pH}$ of supernatants was adjusted to 7.2 points and before using, filtered through a $0.22 \mathrm{~mm}$ Millipore filter (Milli-Q, Millipore, Germany).

\section{Cell culture}

Two human colon cancer cell lines (Caco-2, ATCC, HTB-37 and HT-29, ATCC, HTB-38) and one human epithelial normal cell line with the same embryonic origin (KDR/293) were purchased from Pasteur Institute (national cell bank of Iran) at 13 Feb 2020. Moreover, all of the cell lines were certified recently and also tested for mycoplasma contamination by Pasteur Institute. The purchased cells were cultured in $25 \mathrm{~cm}^{2}$ plastic cell culture flasks and were incubated under standard conditions at $37{ }^{\circ} \mathrm{C}$ in a humidified atmosphere with $5 \% \mathrm{CO}_{2}$ with medium renewal every 1-3 days. The cells were maintained in an RPMI-1640 (HT-29 and Caco-2) or high glucose concentration (4.5 g/L) DMEM (KDR/293) cell culture medium, respectively. Both media were supplemented with $10 \%(\mathrm{v} / \mathrm{v})$ fetal bovine serum (FBS) 
(HyClone, Logan, UT, USA), 8mM L-glutamine, and $1 \%$ of mixture penicillin $(100 \mathrm{IU} / \mathrm{mL})$ and streptomycin $(100 \mathrm{~g} / \mathrm{mL})$ (Sigma, St Louis, MO, USA).

\section{MTT assay}

Cell viability in treated and untreated cell lines was determined by the 3-(4,5-dimethylthiazole-2-yl)-2,5-diphenyltetrazolium bromide (MTT) assay (Sigma, St Louis, MO, USA) based on the capacity of viable cells to reduce a tetrazolium colorless salt to purple formazan in mitochondria. At first, the half-maximal inhibitory concentration $\left(\mathrm{IC}_{50}\right)$ for HT-29 and Caco-2 cells was determined using prescreening MTT tests (in the range of 10 to $100 \mu \mathrm{g} / \mathrm{mL}$ ) at 24 and $48 \mathrm{~h}$. Briefly, the cells were washed twice with phosphate-buffered saline (PBS) (Sigma, St Louis, MO, USA) and trypsinized by adding 1 $\mathrm{mL}$ of trypsin/EDTA (Sigma, St Louis, MO, USA) solution. The cells were plated into 96 well plates at $1.2 \times 10^{4}$ cells per well and added $200 \mu \mathrm{L}$ of the growth medium, incubated for 24-h. After cell attachment, the medium was carefully removed from each well and the cells were treated with an effective dose $\left(\mathrm{IC}_{50}\right)$ of cell-free bacterial supernatant and growth medium. After 24 or $48 \mathrm{~h}$ (determined time point) incubation, $50 \mu \mathrm{L}$ of MTT reagent and $150 \mu \mathrm{L}$ of fresh growth medium were added to each well and plates returned to the incubator for $4 \mathrm{~h}$. Then, the medium of each well was carefully removed and 200 $\mu \mathrm{L}$ of dimethyl sulfoxide (Merck, Germany) and $25 \mu \mathrm{L}$ of Sorenson buffer $(0.1 \mathrm{~mol} / \mathrm{L}$ glycine, $0.1 \mathrm{~mol} / \mathrm{L} \mathrm{NaCl}, \mathrm{pH}$ 10.5) were added to each well and kept for $15 \mathrm{~min}$ in the dark condition at room temperature. The absorbance was determined using an enzyme-linked immune-sorbent assay plate reader (ELx 800; Biotek, Winooski, VT, USA) at $570 \mathrm{~nm}$. The growth inhibitory effects of supernatant were calculated according to the following formula: the growth inhibition ratio $=[$ (the absorbance of the blank control group - the absorbance of experimental group)/ the absorbance of blank control group] $\times 100 \%[24,25]$. To compare the effect of MRS, as bacteria culture media (negative control), with studied bacteria supernatants, both cancerous and normal cells were treated by methanolic extract of intact MRS media that prepared similar to bacteria supernatants. After lyophilization of methanolic extract of MRS media $(50 \mathrm{~mL})$, the obtained dried materials were $18 \mathrm{mg}$. Moreover, 5-fluorouracil (5-FU) as an approved anticancer drug ( $7 \mu \mathrm{L} /$ well of 96 -well plate) was used as the positive control.

\section{Flow cytometry}

Three $\mathrm{mL}$ of growth medium including $1.2 \times 10^{5}$ cells was cultured in 6-well culture plates and incubated at growth condition. After $24 \mathrm{~h}$, the cells were treated with $3 \mathrm{~mL}$ of the sterile growth medium containing determined dried materials of supernatant or 5-FU, as the positive control group, and incubated in the growth condition based on the determined time point. The treated/untreated control cells were detached by trypsin-EDTA, and supernatants were discarded by centrifugation at $900 \mathrm{rpm}$ for $10 \mathrm{~min}$. Finally, for detection of apoptosis, the cells were stained with Annexin V-FITC/Propidium iodide (PI) apoptosis kit (eBioscience, San Diego, CA, USA) according to the manufacturer's instructions, and data analysis was conducted using CELL Quest Pro software (BD Biosciences, San Jose, CA, USA). After performing the flow cytometry, the cell populations were defined using quadrant gates. The number of cells in each quadrant represented quadrant 1 (Q1): necrotic cells (Annexin V-/PI+); quadrant 2 (Q2): late apoptotic cells (Annexin $\mathrm{V}+/ \mathrm{PI}+$ ); quadrant 3 (Q3): early apoptotic cells (Annexin $\mathrm{V}+/ \mathrm{PI}-$ ); and quadrant 4 (Q4): live cells (Annexin V-/PI-) [26, 27]. Each experiment was repeated 2 times with triplicate samples. All of the analyses were performed using 150,000 cells at a rate of $900 \mathrm{cell} / \mathrm{sec}$.

\section{Quantitative real-time PCR analysis}

All untreated/treated cells were washed three times with PBS ( $\mathrm{pH} 7.2)$ and total RNA was extracted from cells by direct lysis using $1 \mathrm{~mL}$ ice cold RNX-plus solution (Sina Clone, Iran), according to the manufacturer's instruments. The obtained total RNA was solved in 50 $\mu \mathrm{L}$ DEPC-treated water (Merck, Germany), and the quantity and quality of total RNA were evaluated by UV spectrophotometry and agarose gel electrophoresis, respectively. Complementary DNA (cDNA) was synthesized using one microgram of isolated RNA by Prime Script RT Reagent kit (Takara Bio Inc, Tokyo, Japan) according to the manufacturer's instructions. The specific primers for each gene including $\mathrm{Bcl}$ 2, BAD, Fas-R, caspase-3, caspase-8, caspase-9, and GAPDH as housekeeping gene were designed [10]. All of the amplification reactions were carried out in triplicate for each sample, and every experiment mixture $(20 \mu \mathrm{L})$, containing $10 \mu \mathrm{L}$ SYBR Green PCR master mix (Takara Bio Inc, Tokyo, Japan), $1 \mu \mathrm{L}$ cDNA $(1 \mu \mathrm{g} / \mu \mathrm{L}), 1$ $\mu \mathrm{L}$ primer (forward and reverse), and $0.8 \mu \mathrm{L} 6$-carboxy$\mathrm{X}$-rhodamine (ROX as reference dye), was subjected to ABI-step I plus (Applied Biosystems, Foster City, CA, USA) instrument. One cycle at $95{ }^{\circ} \mathrm{C}$ for $5 \mathrm{~min}$ followed by 40 cycles at $95^{\circ} \mathrm{C}$ for $20 \mathrm{~s}, 60^{\circ} \mathrm{C}$ for $35 \mathrm{~s}$, and $72{ }^{\circ} \mathrm{C}$ for $10 \mathrm{~s}$ were selected as thermal cycling condition. Pfaffle method was used for interpretation of the results and the threshold cycle values were normalized to the expression rate of glyceraldehyde 3-phosphate dehydrogenase (GAPDH) [28]. 


\section{Statistical analysis}

The statistical package for the social sciences (SPSS Inc. Chicago, IL, USA version 16.0) was used for the statistical analysis. One-way ANOVA and Tukey's post hoc test were performed for analyzing differences between all treatments and multiple mean comparisons, respectively. Statistical significance was considered to be $P \leq 0.05$.

\section{Results}

The $\mathrm{IC}_{50} \mathrm{~s}$ after treatment by prepared cell-free supernatants of bifidobacteria were determined a range between $65 \mu \mathrm{g} / \mathrm{mL}$ to $80 \mu \mathrm{g} / \mathrm{mL}$ for HT-29 and Caco- 2 cells at $48 \mathrm{~h}$ and the control group (KDR/293 cells) were treated with the highest determined concentration $(80 \mu \mathrm{g} / \mathrm{mL})$.

After treatment by cell-free supernatant of all studied bifidobacteria species and 5-FU, the survival rates of colon cancer cells were significantly decreased in comparison to control groups. The survival rate of the HT-29 cell line after treatment by bifidobacteria was between 15.88 and $70.43 \%$ and in the Caco- 2 cell line was 28.19 to $55.45 \%$. Also, the positive control group (5-FU) showed 65.07 and $51.77 \%$ survival rates in HT-29 and Caco-2 cells, respectively (Fig. 1; Table 1).
Flow cytometry was used for the detection of apoptotic rates quantitatively with Annexin V-FITC/PI staining. According to the results of the present study, treatment of cancer cell lines with determined $\mathrm{IC}_{50}$ of methanolic extracts of bifidobacteria secretion metabolites increased the percentage of cells in early and late apoptosis phases compared with the control and normal KDR/293 cells. The highest percentage of induced apoptosis (early and late apoptosis) in the HT-29 cancer cell lines belonged to B. bifidum (53.32\%) and the lowest was in B. angulatum (24.83\%) (Fig. 2). Moreover, in Caco- 2 cells, the percent of apoptosis was 79.78, $68.07,68.36,37.79$, and 12.98 in B. bifidum, B. animalis subsp. lactis, B. animalis subsp. animalis, B. adolescentis, and $B$.angulatum, respectively (Fig. 3). Also, in normal cells, the highest and lowest percentages of apoptosis were in B. adolescentis (26.67\%) and B. angulatum (8.03\%) groups, respectively. As well, 5-FU induced $52.77 \%$ (HT-29 cells), 34.36\% (Caco-2 cells) and $28.64 \%$ (KDR/293 cells) apoptosis (Fig. 4). As well, Fig. 5 showed the quantitative alterations (necrosis and early/late apoptosis) of treated/untreated cancerous and normal cells and the statistical analysis between
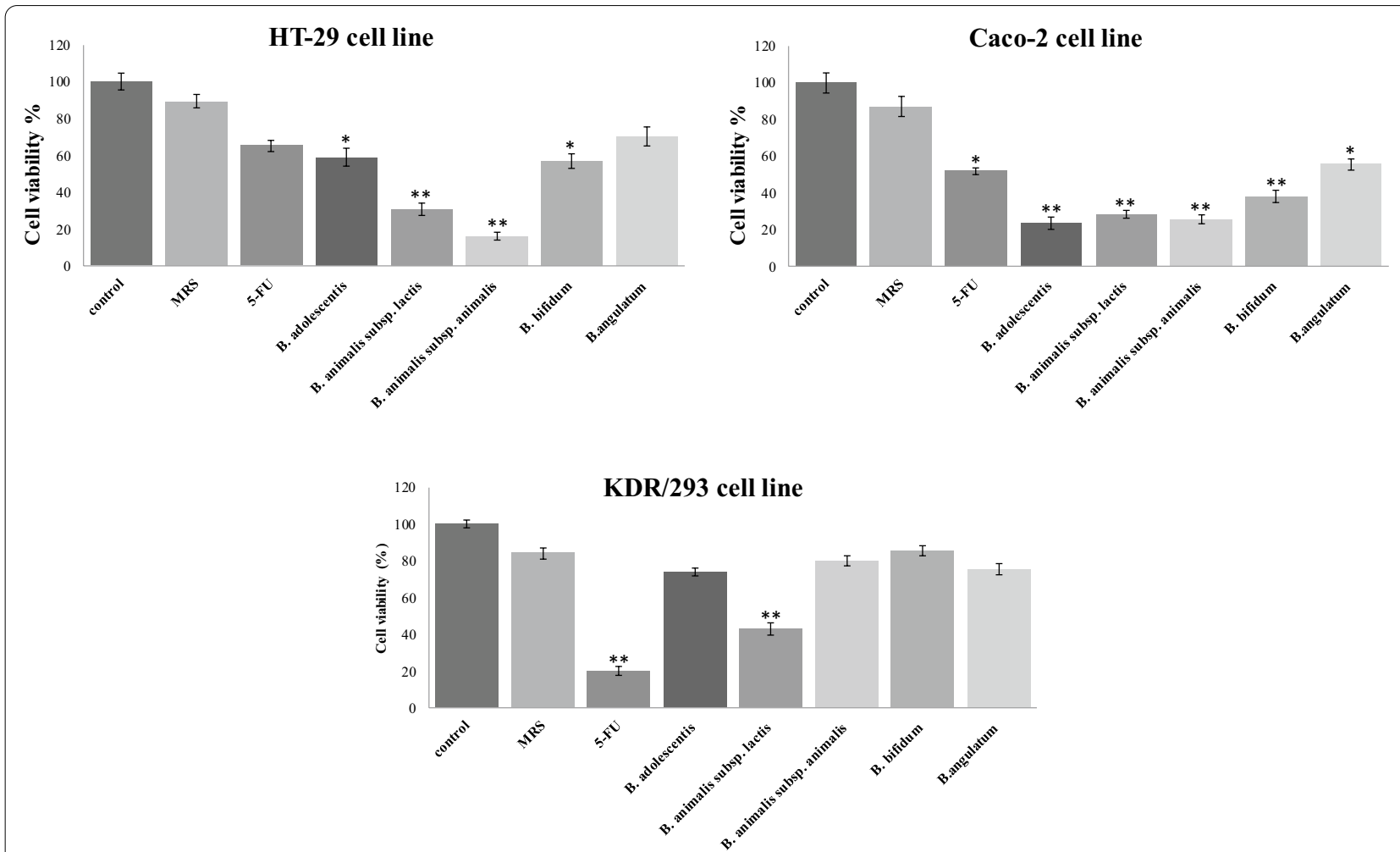

Fig. 1 Effects of secretion metabolites of different bifidobacteria species containing indicated concentrations of dried materials from the methanolic extract on the viability of HT-29, Caco-2 cancer cell lines, and KDR/293 normal cells for $48 \mathrm{~h}$ incubation by MTT assay test. Untreated cells and methanolic extract of MRS media were used as negative control, and 5-FU ( $7 \mu \mathrm{L} /$ well of 96-well plate) was used as positive control. Data are expressed as mean viability \pm S.D. Asterisks signify statistically significant differences $\left({ }^{*} P \leq 0.05,{ }^{* *} P \leq 0.01\right)$ 
Table 1 MTT assay data of treated cells from triplicate examinations and the statistical analysis in comparison to control group

\begin{tabular}{|c|c|c|c|c|c|c|}
\hline \multirow[t]{2}{*}{ Treatments } & \multicolumn{6}{|c|}{ Cell lines } \\
\hline & HT-29 & P-value & Caco-2 & P-value & KDR-293 & P-value \\
\hline Control & 100 & - & 100 & - & 100 & - \\
\hline \multirow[t]{3}{*}{ MRS } & 90.13 & 0.98 & 89.09 & 0.83 & 85.15 & 0.77 \\
\hline & 88.19 & & 85.67 & & 86.51 & \\
\hline & 89.43 & & 85.89 & & 84.12 & \\
\hline \multirow[t]{3}{*}{ 5-FU } & 65.21 & 0.77 & 52.12 & $0.03^{*}$ & 21.44 & $0.002^{* *}$ \\
\hline & 66.89 & & 53.55 & & 19.87 & \\
\hline & 63.11 & & 49.64 & & 20.91 & \\
\hline \multirow[t]{3}{*}{ B. adolescentis } & 60.47 & $0.04^{*}$ & 23.55 & $0.006^{* *}$ & 75.21 & 0.65 \\
\hline & 57.54 & & 22.41 & & 73.12 & \\
\hline & 58.56 & & 24.43 & & 74.03 & \\
\hline \multirow[t]{3}{*}{ B. animalis subsp. lactis } & 32.25 & $0.008^{* *}$ & 29.45 & $0.008^{* *}$ & 45.08 & $0.007^{* *}$ \\
\hline & 29.08 & & 28.11 & & 41.54 & \\
\hline & 30.23 & & 27.03 & & 42.89 & \\
\hline \multirow[t]{3}{*}{ B. animalis subsp. animalis } & 18.01 & $0.003^{* *}$ & 23.05 & $0.007^{* *}$ & 78.09 & 0.81 \\
\hline & 16.45 & & 27.08 & & 83.14 & \\
\hline & 13.18 & & 26.15 & & 80.32 & \\
\hline \multirow[t]{3}{*}{ B. bifidum } & 56.38 & $0.03^{*}$ & 40.23 & $0.009^{* *}$ & 87.02 & 0.91 \\
\hline & 57.95 & & 38.31 & & 84.11 & \\
\hline & 55.91 & & 36.04 & & 86.21 & \\
\hline \multirow[t]{3}{*}{ B.angulatum } & 72.44 & 0.82 & 55.01 & $0.04^{*}$ & 73.08 & 0.79 \\
\hline & 70.36 & & 53.11 & & 77.12 & \\
\hline & 68.51 & & 58.23 & & 75.33 & \\
\hline
\end{tabular}

${ }^{*} \mathrm{P} \leq 0.05$ and ${ }^{* *} \mathrm{P} \leq 0.01$ indicate significant and highly significant increase in cell death vs. the control group

different groups after treatment with bifidobacteria secretion metabolites (Fig. 5).

Figure 6 indicates the expression level of pro-apoptotic (caspase-3, caspase-8, caspase-9, Fas- $R$, and $\mathrm{BAD}$ ) and anti-apoptotic (Bcl-2) key genes in the colon and normal cell lines after treatment with methanolic extract of Bifidobacterial supernatants and 5-FU compared with untreated control cells. 5-FU significantly increased the expression level of pro-apoptotic genes except for caspase-9 and decreased Bcl-2 as an antiapoptotic gene. The expression level of the BAD, caspase-3, caspase-8, caspase-9, and Fas- $R$ genes was increased by bacterial supernatants, but only in some species was statistically significant. Treatment with $B$. adolescentis significantly up-regulated the expression level of caspase-8, Fas-R, and BAD genes in HT-29 and Caco- 2 cancer cell lines. Also, the caspase- 9 and Bcl-2 gene expression levels were significantly up-regulated and down-regulated in the HT-29 and Caco-2 cell lines, respectively. Moreover, B. angulatum could not up-regulate the expression level of all genes significantly, except for Fas-R.

\section{Discussion}

Probiotics are being investigated for their different health beneficial effects. Anticancer or cancer-preventive effects of different probiotic species are the most beneficial properties of them and according to these findings, the consumption of probiotics or prebiotics is suggested as a promising approach for the prevention and treatment of CRC. In this way, different mechanisms have been proposed for anticancer properties of probiotics such as the production of antitumorigenic or anti-mutagenic compounds, antitoxin effects against different toxins, antimicrobial effects, production of the short-chain fatty acids (SCFA), trophic effects on enterocytes, and improvement of intestinal barrier function and microflora [11, 21, 29].

It is recently reported that probiotic microorganisms, especially Lactobacillus and Bifidobacterium species exert anticancer effects through the production of antioxidative enzymes, binding to reactive oxygen species, chelating heavy metals, and neutralizing different carcinogens. Furthermore, they can regulate the cell cycle in cancer cells and inhibit their proliferation and make them susceptible to apoptosis [13, 27, 30]. 


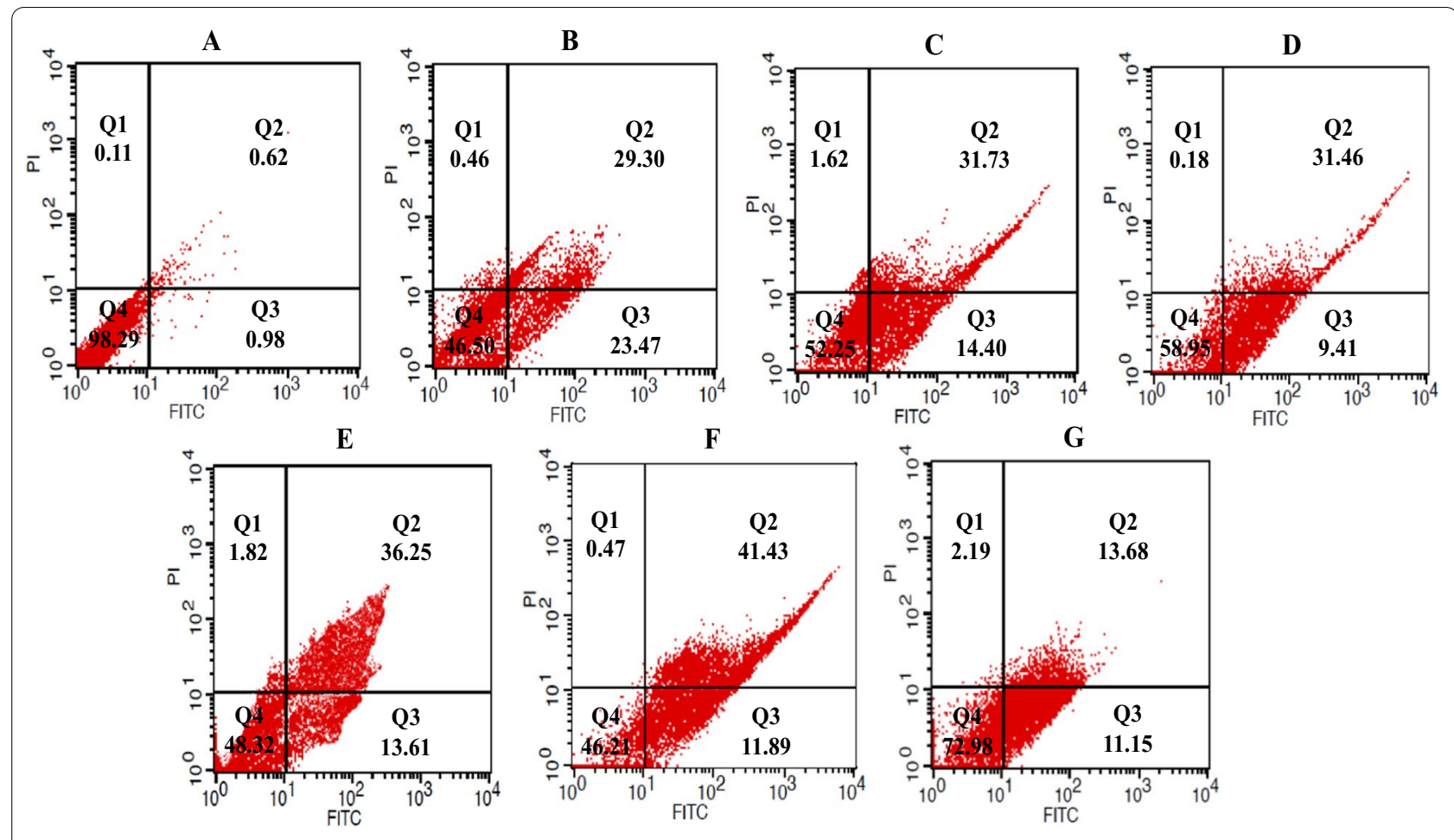

Fig. 2 Flow cytometric analysis of treated/untreated HT-29 cancerous cells. Cells were treated with FITC-Annexin V in combination with PI to detect apoptosis and necrosis before being subjected for analysis by flow cytometry. Dots with Annexin V-/PI+ (Q1), Annexin V+/PI+ (Q2), Annexin V+/ $\mathrm{Pl}-(\mathrm{Q} 3)$, and Annexin $\mathrm{V}-/ \mathrm{PI}-(\mathrm{Q} 4)$ and feature represent necrotic, late apoptotic, early apoptotic, and viable intact cells, respectively. a Control; b 5 -FU; c B. adolescentis; $\mathbf{d}$ B. animalis subsp. lactis; e B. animalis subsp. animalis; $\mathbf{f}$ B. bifidum; $\mathbf{g}$ B. angulatum

Apoptosis is a controlled process in which some defective cells are selectively eliminated and plays an important role in controlling cell numbers. Many cancer cell types including CRC are resistant to apoptosis and have uncontrolled proliferation. As well, different studies showed that bifidobacteria can interrupt this resistance via upregulation and downregulation of effective genes with pro-apoptotic and anti-apoptotic activities [30, 31]. Therefore, the regulation of cell proliferation and apoptosis can be one of the main cancer treatment strategies, and probiotics are reported to be involved in the regulation of cell apoptosis and proliferation [11,31].

To the best of our knowledge, this is the first study that investigated the effects of secretion metabolites from different bifidobacteria species on colorectal cancer cell lines. In the present study, we investigated the potential anticancer activities of five species of bifidobacteria on HT-29 and Caco-2 cell lines. Our findings showed that the secretion metabolites of bifidobacteria species can induce intrinsic and extrinsic apoptosis pathways in human colorectal cancer cells. Also, in HT-29 cancer cell lines, the highest and lowest levels of apoptosis were induced by $B$. bifidum and B. angulatum, respectively. The highest percentages of induced apoptosis in Caco- 2 cells belonged to $B$. bifidum, followed by $B$. animalis subsp. Lactis and B. animalis subsp. Animalis (Fig. 5). Similarly, You et al. and Ku et al. suggested that B.bifidum strains inhibited the growth of several cancer cell lines including HT-29 [32, 33]. B. bifidum has been previously reported to be anti-proliferative and protective effects against preneoplastic lesions in animal models of colorectal carcinogenesis [8]. The anti-proliferative properties of $B$. bifidum on cancer cell lines are considered as an example of the interaction between Bifidobacterium spp. and host cells [34]. The interactions between B. bifidum and colon cancer cells lead to the suppression of cancer cell growth that indicates anticancer or antitumor effects. It is reported that whole peptidoglycan, a 


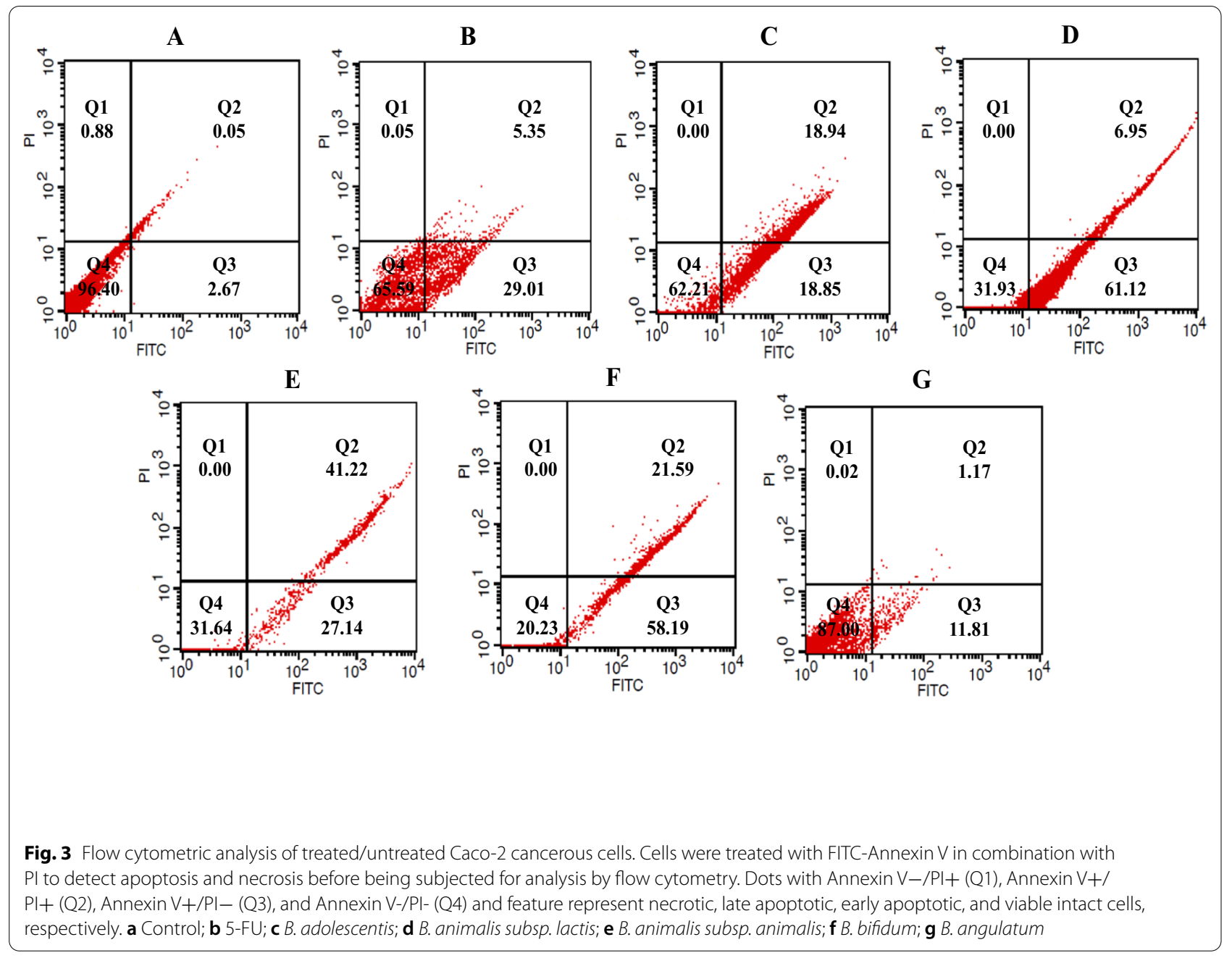

metabolite produced by B.bifidum, was capable to activate macrophages to produce large amounts of cytotoxic molecules including TNF- $\alpha$, IL-6, and IL-12 [35]. By considering the antitumor activity of these mediators, the cytotoxic molecules secreted by activated macrophages mediate the antitumor effects of the whole peptidoglycan. However, in this study, the main effective metabolites of $B$.bifidum were not characterized and further studies are necessary to elucidate the main effective compound(s) and the exact role of $B$. bifidum as a preventive or therapeutic agent in CRC.

The results of the present study indicated that B. adolescentis can significantly inhibit the proliferation of human colon cancer cell lines, including HT-29, and Caco-2, which is similar to the results of kim et al. [36]. Similarly, Lee et al. demonstrated that the butanol extract of $B$. adolescentis SPM0212 can decrease the proliferation of three human colon cancer cell lines, Caco2, HT-29, and SW480 in a dose-dependent manner. In addition, their findings showed that the treatment of cancer cells with butanol extract of $B$. adolescentis SPM0212 triggers macrophage activation and significantly enhances the production of TNF- $\alpha$ and NO as two mediators of the immune system with cytotoxic effects on tumor cells [21]. Also, Asadollahi et al. demonstrated that the treatment of LS174T cancer cells and CRC mice model by a cocktail of 5 strains of Bifidobacteria has significant protective and anti-cancer effects via downregulation of effective genes such as EGFR, HER-2, and PTGS-2 (COX-2) and suggested as the most efficient treatment in CRC [20]. Moreover, administration of live Lactobacillus casei ATCC 393 on murine (CT26) and HT-29 colon cancer cell lines significantly decreased the cell viability and showed potent anti-proliferative effects. Besides, the tumor-suppressive effects of Lactobacillus case $i$ were associated to 60 fold higher mRNA expression of TRAIL (Tumor necrosis factor-related apoptosisinducing ligand), as an effective gene in the activation of extrinsic apoptosis signaling pathway, and 10 fold lower mRNA expression of cyclin D1 (a protein required for 


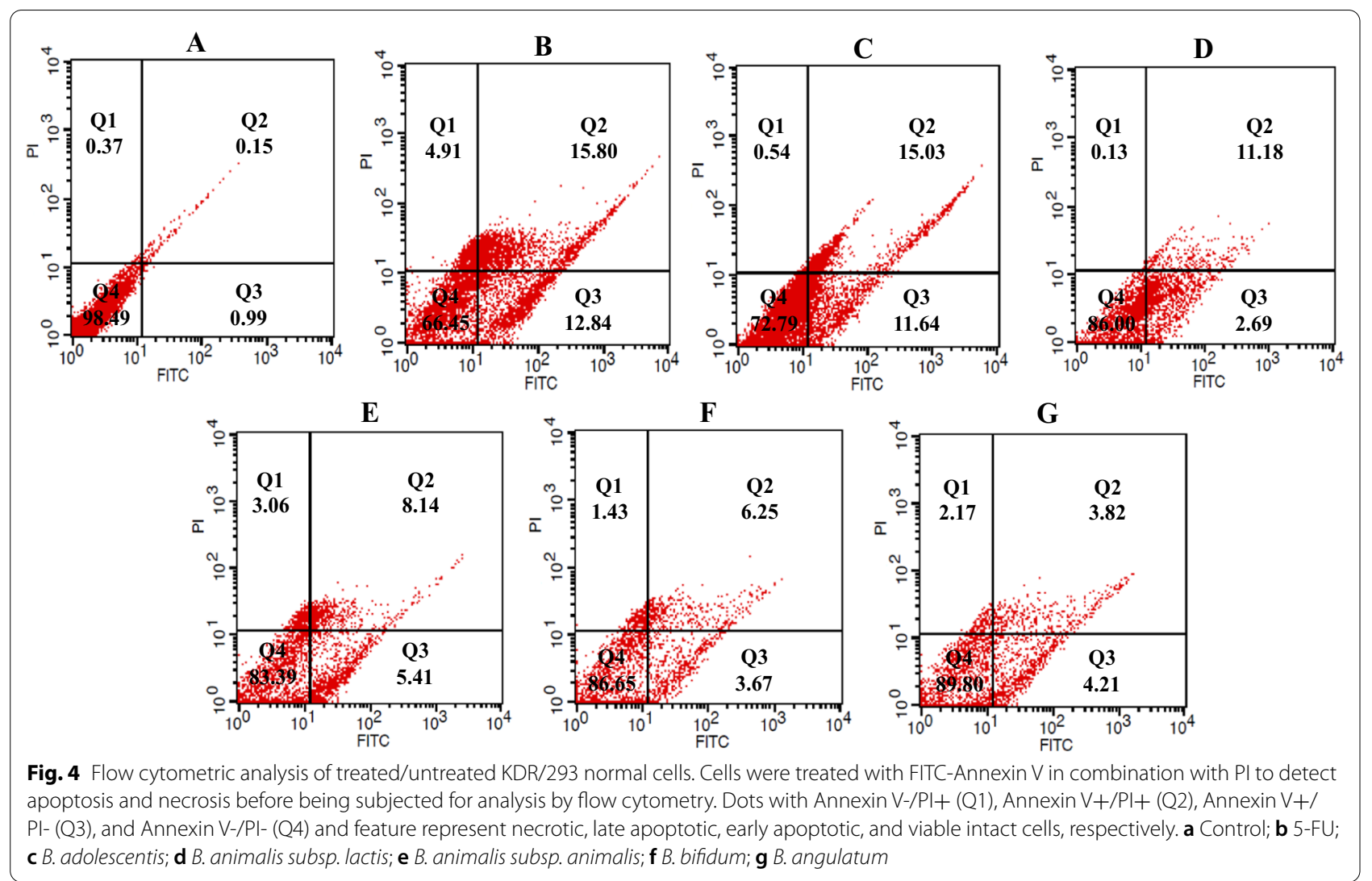

progression through the G1 phase of the cell cycle), and BIRC5 (Baculoviral IAP repeat-containing 5), that encode the anti-apoptotic protein Survivin [27]. Likewise, Bibalan et al. examined the antiproliferative and anti-pathogenic effects of the Lactic acid bacteria isolated from fecal samples of healthy humans on the HT-29 cell lines. They showed that amongst the 13 Lactobacillus isolates, L. plantarum 03 has significant and maximum antiproliferative activities. In addition, they suggested that administration of a combination of Lactobacillus species is more effective and required for activation of the biological defense system [37].

In the present study, the investigation of underlying mechanisms revealed that the $B$. adolescentis is able to trigger apoptosis by upregulation of caspase-8, Fas-R, and BAD gene expression in HT-29 and, Caco-2 cancer cell lines. Surface receptors for extrinsic apoptosis, such as TNF- $\alpha$, are produced by immune system cells and Fas, which are able to activate the cytosolic protease and caspase- 8 . Then, the caspase- 8 activates caspase- 3 , caspase-6, and caspase-7 that leading to extrinsic apoptosis induction [38]. In this way, Kim et al. revealed that $B$. adolescentis enhances the production of TNF- $\alpha$, as a cytokine that induces apoptosis, and their results supported our findings about the induction of apoptosis by this bacteria species[36]. Furthermore, B. adolescentis has been used as a vehicle for systemic delivery of the antiangiogenic protein endostatin, and systemic administration of its spores can strongly inhibit angiogenesis and reduce tumor growth [39]. Moreover, B. adolescentis effectively increased the expression level of the caspase- 9 gene in HT-29 cells and induced the intrinsic apoptosis pathway. Caspase- 9 has an important role in the intrinsic apoptosis pathway and its activation is related to mitochondrial outer membrane permeabilization and release of cytochrome $c$ [40].

Furthermore, our findings revealed that $B$. adolescentis can significantly reduce the expression level of the antiapoptotic gene, $\mathrm{Bcl}-2$, in Caco-2 cell lines. Generally, apoptosis occurs via two major pathways, the intrinsic 

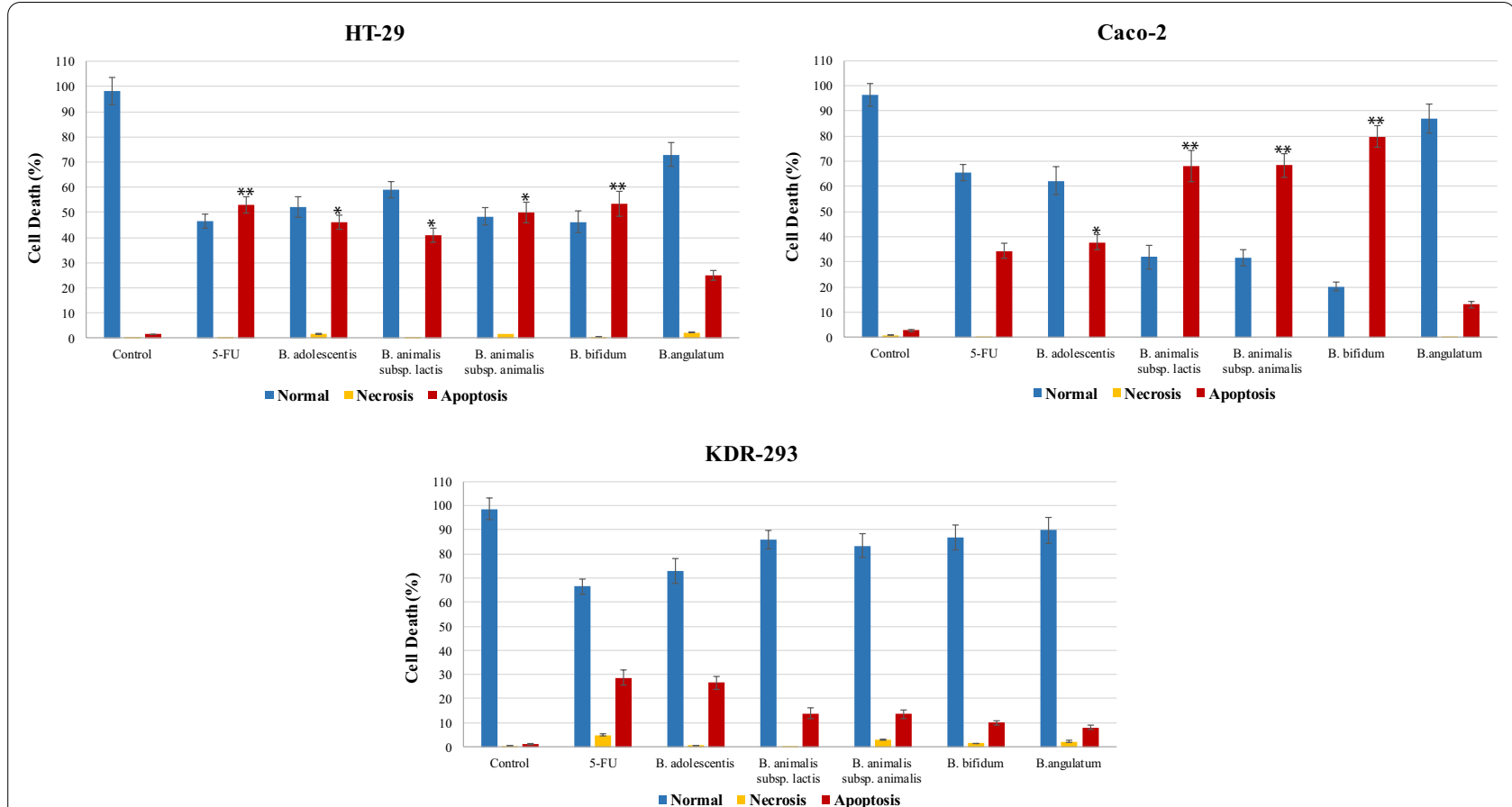

Fig. 5 Bar plots demonstrate quantitative alterations (necrosis and early/late apoptosis) of treated/untreated cancerous and normal cell lines from flow cytometry analysis. Asterisks signify statistically significant differences in comparision to normal cells $\left({ }^{*} P \leq 0.05,{ }^{* *} P \leq 0.01\right)$

pathway (mitochondria-dependent) and the extrinsic pathways (death receptor-dependent). BCL-2 family proteins are involved in the intrinsic apoptosis pathway and composed of two groups of proteins; the first group is proteins with pro-apoptotic properties such as BAX and BAK, and the second group is proteins with antiapoptotic properties such as BCL-2 and BCL-XL. Thus, the lower expression of BCL-2 which has anti-apoptotic activity can trigger the apoptosis pathway $[40,41]$.

Moreover, other species of bifidobacteria, B. animalis, have demonstrated anti-mutagenic activity during growth in the MRS broth which antagonizing the action of the carcinogen 2-amino-3-methylimidazo [4, 5-f] quinolone [42]. Numerous studies have focused on the potential effects of $B$. animalis strain on cancer cell lines, but the precise mechanism whereby this strain exert their antitumorigenic effects remains undetermined yet [43, 44].

In the present study, B. bifidum, followed by two subspecies of $B$. animalis and lactis exerted the highest percentage of apoptosis in the Caco-2 cell lines. Based on different studies, NF- $\mathrm{kB}$ has a pivotal role in inflammation and can up-regulate several genes involved in apoptosis suppression. These important effects indicate its critical role in the inflammation-related carcinogenesis [45]. It is reported that $B$. animalis subspecies lactis exert preventive effects on colitis-associated colon cancer by inhibition of NF-kB activity [46]. As well, Fahmy et al. revealed that treatment of $C R C$ mice with $B$. longum, isolated from women breast milk, decrease NF-kB and IL-6 concentration. On the other hand, administration of this bacteria increased IL-1 $\beta$ concentration and resulted in the decline of aberrant crypt foci number in CRC-mice and improve necrosis and fibrosis of the colon cells [47]. Since the NF- $\mathrm{kB}$ is involved in cell proliferation and also plays a critical role in the inflammatory process, it provides a possible mechanistic link between inflammation and cancer [48]. However, we did not evaluate the activity of NF- $\mathrm{kB}$, and further studies are required to investigate the effects of Bifidobacterium strains on NF- $\mathrm{KB}$ signaling.

There are some limitations to the present study. Firstly, the anticancer effects of bifidobacteria species on other types of cancer cell lines were not investigated, and additionally, the specific compound(s) of the secretion metabolites of bifidobacteria species, which is involved in the antitumor activity, was not determined. Moreover, in the present study the flow cytometry plots spilled over each other and the compensation study to separate 

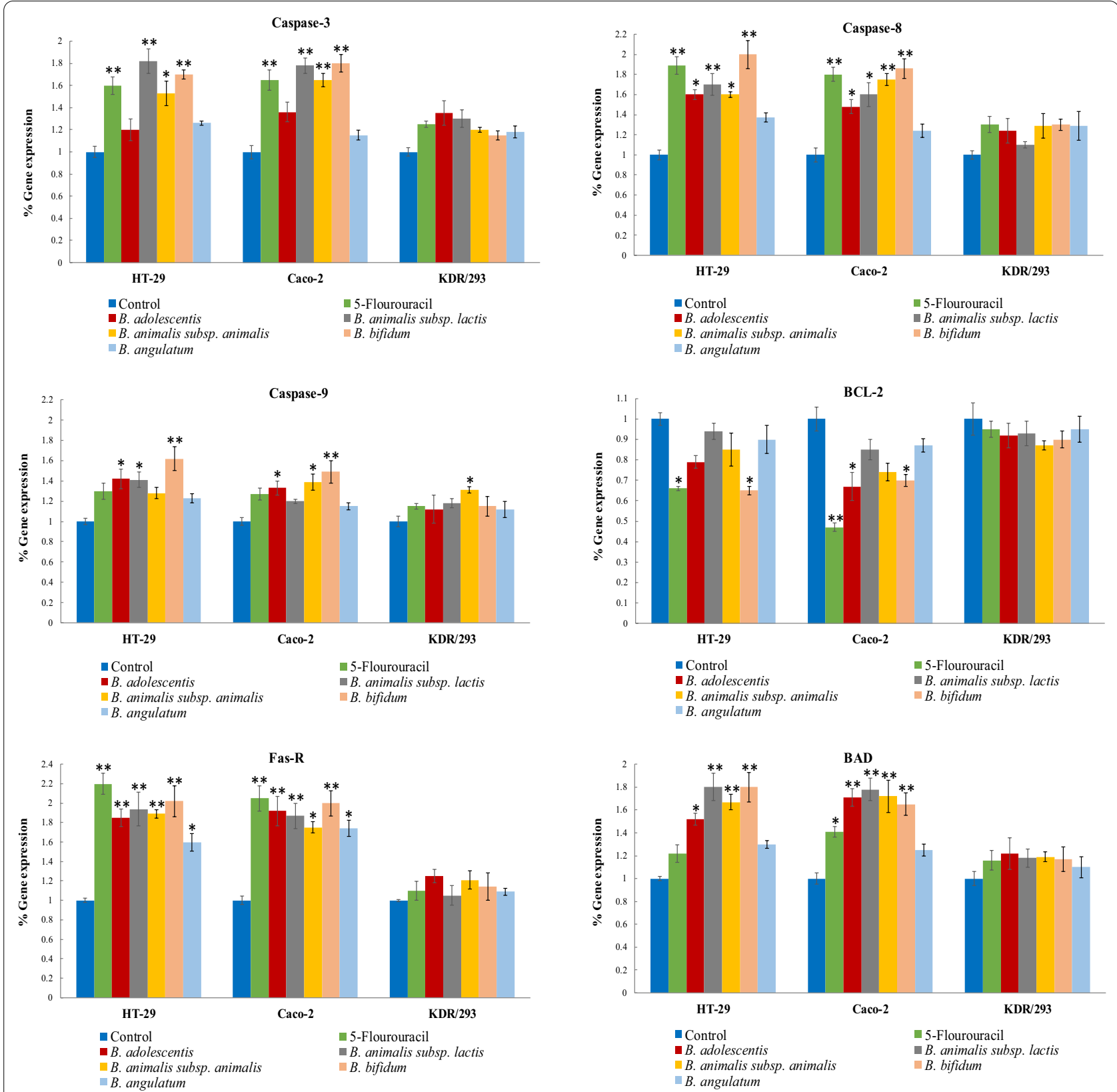

Fig. 6 Main intrinsic and extrinsic apoptosis pathway gene expression ratio in the HT-29, Caco-2, cancer cells and KDR/293 normal cells that treated with indicated concentrations of dried materials from the methanolic extract secretion metabolites of bifidobacteria and with 5-FU as positive control group for $48 \mathrm{~h}$. Target genes were normalized to GAPDH as housekeeping control gene. All experiments were performed in triplicate $(n=3)$ and statistic significances were accepted at $P \leq 0.05 .{ }^{*} P \leq 0.05,{ }^{* *} P \leq 0.01$, as compared to control

the cell populations was not performed. Also, due to the purpose of the study and the financial constraints, the effects of Bifidobacteria species on protein levels were not investigated.

In conclusion, the present study confirmed the anticancer and apoptosis-inducing effects of secretion metabolites of bifidobacteria species on colon cancer cell lines with less adverse effects on normal epithelial cells (KDR/293). Besides, the proposed mechanisms for the CRC preventive effects of bifidobacteria species are down-regulation and up-regulation of anti- and proapoptotic factors. However, performing more studies is recommended to determine the exact mechanisms of probiotics in human colon cancer. 


\begin{abstract}
Abbreviations
BIRC5: Baculoviral IAP repeat containing 5; CDNA: Complementary DNA; CRC: Colorectal cancer; DMEM: Dulbecco's Modified Eagle's Medium; ELISA: Enzyme-linked immunosorbent assay; GAPDH: Glyceraldehyde 3-phosphate dehydrogenase; $I C_{50}$ : Half-maximal inhibitory concentration; IROST: Iranian Research Organization for Science and Technology; MRS: Man-Rogosa agar; MTT: 3-(4,5-Dimethylthiazol-2-yl)-2,5-diphenyltetrazolium bromide; PBS: Phosphate-buffered saline; PI: Propidium iodide; PTCC: Persian Type Culture Collection; RPMI: Roswell Park Memorial Institute medium; RT-PCR: Real-time polymerase chain reaction.; TRAIL: Tumor necrosis factor-related apoptosisinducing ligand; 5-FU: 5-Fluorouracil.
\end{abstract}

\section{Acknowledgements}

\section{Not applicable.}

\section{Authors' contributions}

ZF, MHF, AS conceived and designed the experiments; MHF, SI performed the experiments and analyzed the data; AS, AHK reviewed the paper and provided comments. All authors read and approved the final manuscript.

\section{Funding}

This research did not receive any specific grant from funding agencies in the public, commercial, or not-for-profit sectors.

\section{Availability of data and materials}

The data that support the findings of this study are available from the corresponding author upon reasonable request.

\section{Declarations}

\section{Ethics approval and consent to participate}

Not applicable.

\section{Consent for publication}

Not applicable.

\section{Competing interests}

The authors declare that they have no competing interests.

\begin{abstract}
Author details
${ }^{1}$ Food (Salt) Safety Research Center, School of Nutrition and Food Sciences, Semnan University of Medical Sciences, Semnan, Iran. ${ }^{2}$ Department of Medical Biotechnology and Nanotechnology, School of Medicine, Zanjan University of Medical Sciences, Zanjan, Iran. ${ }^{3}$ Department of Nutritional Sciences, School of Nutritional Sciences and Food Technology, Kermanshah University of Medical Sciences, Kermanshah, Iran. ${ }^{4}$ Student Research Committee, Tabriz University of Medical Sciences, Tabriz, Iran. ${ }^{5}$ Drug Applied Research Center, Tabriz University of Medical Sciences, Tabriz, Iran. ${ }^{6}$ Department of Medical Nanotechnology, Faculty of Advanced Medical Science, Tabriz University of Medical Sciences, Tabriz, Iran. ${ }^{7}$ Department of Nutritional Sciences, School of Nutritional Sciences and Food Technologies, Kermanshah University of Medical Sciences, Isar Sq., next to Farabi Hospital, P.O. Box 6719851351, Kermanshah, Iran.
\end{abstract}

Received: 30 November 2020 Accepted: 5 May 2021

Published online: 12 May 2021

\section{References}

1. Siegel RL, Miller KD, Jemal A. Cancer statistics 2019. Cancer J Clin. 2019;69(1):7-34.

2. Thun MJ, DeLancey JO, Center MM, Jemal A, Ward EM. The global burden of cancer: priorities for prevention. Carcinogenesis. 2010;31(1):100-10.

3. Uccello M, Malaguarnera G, Basile F, D'agata V, Malaguarnera M, Bertino G, Vacante M, Drago F, Biondi A. Potential role of probiotics on colorectal cancer prevention. BMC Surg. 2012;12(S1):35.

4. Araghi M, Soerjomataram I, Jenkins M, Brierley J, Morris E, Bray F, Arnold M. Global trends in colorectal cancer mortality: projections to the year 2035. Int J Cancer. 2019;144(12):2992-3000.
5. Brenner AT, Dougherty M, Reuland DS. Colorectal cancer screening in average risk patients. Med Clin. 2017;101(4):755-67.

6. Turner N, Ritchie L, Bresalier R, Chapkin R. The microbiome and colorectal neoplasia: environmental modifiers of dysbiosis. Curr Gastroenterol Rep. 2013;15(9):346.

7. Kuugbee ED, Shang X, Gamallat Y, Bamba D, Awadasseid A, Suliman MA, Zang S, Ma Y, Chiwala G, Xin Y. Structural change in microbiota by a probiotic cocktail enhances the gut barrier and reduces cancer via TLR2 signaling in a rat model of colon cancer. Dig Dis Sci. 2016;61(10):2908-20.

8. Mohania D, Kansal VK, Kruzliak P, Kumari A. Probiotic Dahi containing Lactobacillus acidophilus and Bifidobacterium bifidum modulates the formation of aberrant crypt foci, mucin-depleted foci, and cell proliferation on 1, 2-dimethylhydrazine-induced colorectal carcinogenesis in Wistar rats. Rejuvenation Res. 2014;17(4):325-33.

9. Saber A, Alipour B, Faghfoori Z, Khosroushahi AY. Secretion metabolites of dairy Kluyveromyces marxianus AS41 isolated as probiotic, induces apoptosis in different human cancer cell lines and exhibit anti-pathogenic effects. J Funct Foods. 2017;34:408-21.

10. Saber A, Alipour B, Faghfoori Z, Khosroushahi AY. Secretion metabolites of probiotic yeast, Pichia kudriavzevii AS-12, induces apoptosis pathways in human colorectal cancer cell lines. Nutr Res. 2017:41:36-46.

11. Saber A, Alipour B, Faghfoori Z, Yari Khosroushahi A. Cellular and molecular effects of yeast probiotics on cancer. Crit Rev Microbiol. 2017:43(1):96-115.

12. Kato K, Odamaki T, Mitsuyama E, Sugahara H, Xiao J-z, Osawa R. Agerelated changes in the composition of gut Bifidobacterium species. Curr Microbiol. 2017;74(8):987-95.

13. Hidalgo-Cantabrana C, Delgado S, Ruiz L, Ruas-Madiedo P, Sánchez B, Margolles A. Bifidobacteria and their health-promoting effects. Microbiol Spectr. 2017. https://doi.org/10.1128/microbiolspec. BAD-0010-2016.

14. Tojo R, Suárez A, Clemente MG, de los Reyes-Gavilán CG, Margolles A Gueimonde M, Ruas-Madiedo P. Intestinal microbiota in health and disease: role of bifidobacteria in gut homeostasis. World J Gastroenterol. 2014;20(41):15163.

15. Sarkar A, Mandal S. Bifidobacteria-Insight into clinical outcomes and mechanisms of its probiotic action. Microbiol Res. 2016;192:159-71.

16. Ishizeki S, Sugita M, Takata M, Yaeshima T. Effect of administration of bifidobacteria on intestinal microbiota in low-birth-weight infants and transition of administered bifidobacteria: a comparison between onespecies and three-species administration. Anaerobe. 2013:23:38-44

17. Turroni F, Berry D, Ventura M. Bifidobacteria and their role in the human gut microbiota. Front Microbiol. 2017;6(7):2148.

18. Oberreuther-Moschner DL, Jahreis G, Rechkemmer G, Pool-Zobel BL. Dietary intervention with the probiotics Lactobacillus acidophilus 145 and Bifidobacterium longum 913 modulates the potential of human faecal water to induce damage in HT-29clone19A cells. Br J Nutr. 2004;91(6):925-32.

19. Liboredo JC, Anastácio LR, Pelúzio MdCG, Valente FX, Penido LCP, Nicoli JR, Correia MITD. Effect of probiotics on the development of dimethylhydrazine-induced preneoplastic lesions in the mice colon. Acta Cir Bras. 2013;28(5):367-72.

20. Asadollahi P, Ghanavati R, Rohani M, Razavi S, Esghaei M, Talebi M. Anticancer effects of Bifidobacterium species in colon cancer cells and a mouse model of carcinogenesis. PloS one. 2020;15(5):e0232930.

21. Lee DK, Jang S, Kim MJ, Kim JH, Chung MJ, Kim KJ, Ha NJ. Anti-proliferative effects of Bifidobacterium adolescentis SPM0212 extract on human colon cancer cell lines. BMC Cancer. 2008;8:310.

22. Chen C-C, Lin W-C, Kong M-S, Shi HN, Walker WA, Lin C-Y, Huang C-T, Lin Y-C, Jung S-M, Lin T-Y. Oral inoculation of probiotics Lactobacillus acidophilus NCFM suppresses tumour growth both in segmental orthotopic colon cancer and extra-intestinal tissue. Br J Nutr. 2012;107(11):1623-34.

23. Chowdhury I, Tharakan B, Bhat GK. Current concepts in apoptosis: the physiological suicide program revisited. Cell Mol Biol Lett. 2006;11(4):506-25.

24. Finimundy T, Gambato G, Fontana R, Camassola M, Salvador M, Moura S, Hess J, Henriques J, Dillon A, Roesch-Ely M. Aqueous extracts of Lentinula edodes and Pleurotus sajor-caju exhibit high antioxidant capability and promising in vitro antitumor activity. Nutr Res. 2013;33(1):76-84. 
25. Denizot F, Lang R. Rapid colorimetric assay for cell growth and survival: modifications to the tetrazolium dye procedure giving improved sensitivity and reliability. J Immunol Methods. 1986;89(2):271-77.

26. Crowley LC, Marfell BJ, Scott AP, Waterhouse NJ. Quantitation of Apoptosis and Necrosis by Annexin V Binding, Propidium lodide Uptake, and Flow Cytometry. Cold Spring Harb Protoc. 2016;2016:11.

27. Tiptiri-Kourpeti A, Spyridopoulou K, Santarmaki V, Aindelis G, Tompoulidou E, Lamprianidou EE, Saxami G, Ypsilantis P, Lampri ES, Simopoulos C, et al. Lactobacillus casei exerts anti-proliferative effects accompanied by apoptotic cell death and up-regulation of TRAIL in colon carcinoma cells. PLOS ONE. 2016;11(2):e0147960.

28. Pfaffl MW. A new mathematical model for relative quantification in realtime RT-PCR. Nucleic Acids Res. 2001;29(9):e45-5.

29. Hirayama K, Rafter J. The role of probiotic bacteria in cancer prevention. Microbes Infect. 2000;2(6):681-6.

30. Nowak A, Paliwoda A, Błasiak J. Anti-proliferative, pro-apoptotic and antioxidative activity of Lactobacillus and Bifidobacterium strains: A review of mechanisms and therapeutic perspectives. Crit Rev Food Sci Nutr. 2019;59(21):3456-67.

31. Zhong L, Zhang $X$, Covasa M. Emerging roles of lactic acid bacteria in protection against colorectal cancer. World J Gastroenterol. 2014;20(24):7878-86

32. You HJ, Oh D-K, Ji GE. Anticancerogenic effect of a novel chiroinositolcontaining polysaccharide from Bifidobacterium bifidum BGN4. FEMS Microbiol Lett. 2004;240(2):131-36.

33. Ku S, You HJ, Ji GE. Enhancement of anti-tumorigenic polysaccharide production, adhesion, and branch formation of Bifidobacterium bifidum BGN4 by phytic acid. Food Sci Biotechnol. 2009;18(3):749-54.

34. Ku S, Park MS, Ji GE, You HJ. Review on Bifidobacterium bifidum BGN4: functionality and nutraceutical applications as a probiotic microorganism. Int J Mol Sci. 2016;17(9):1544.

35. Wang L-S, Zhu H-M, Zhou D-Y, Wang Y-L, Zhang W-D. Influence of whole peptidoglycan of bifidobacterium on cytotoxic effectors produced by mouse peritoneal macrophages. World J Gastroenterol. 2001;7(3):440-43.

36. Kim Y, Lee D, Kim D, Cho J, Yang J, Chung M, Kim K, Ha N. Inhibition of proliferation in colon cancer cell lines and harmful enzyme activity of colon bacteria by Bifidobacterium adolescentis SPM0212. Arch Pharmacal Res. 2008;31(4):468-73.

37. Hasannejad Bibalan M, Eshaghi M, Rohani M, Esghaei M, DarbanSarokhalil D, Pourshafie MR, Talebi M. Isolates of Lactobacillus plantarum and $L$. reuteri display greater antiproliferative and antipathogenic activity than other Lactobacillus isolates. J Med Microbiol. 2017:66(10):1416-20.

38. Song S, Oh S, Lim K. The proteins ( 12 and $15 \mathrm{kDa}$ ) isolated from heatkilled Lactobacillus plantarum L67 induces apoptosis in HT-29 cells. Cell Biochem Funct. 2015;33(2):89-96.
39. Li X, Fu G-F, Fan Y-R, Liu W-H, Liu X-J, Wang J-J, Xu G-X. Bifidobacterium adolescentis as a delivery system of endostatin for cancer gene therapy: selective inhibitor of angiogenesis and hypoxic tumor growth. Cancer Gene Ther. 2003;10(2):105-11.

40. Pistritto G, Trisciuoglio D, Ceci C, Garufi A, D'Orazi G. Apoptosis as anticancer mechanism: function and dysfunction of its modulators and targeted therapeutic strategies. Aging. 2016;8:603-19.

41. Hata AN, Engelman JA, Faber AC. The BCL2 family: key mediators of the apoptotic response to targeted anticancer therapeutics. Cancer Discov. 2015;5(5):475-87.

42. Tavan E, Cayuela C, Antoine JM, Cassand P. Antimutagenic activities of various lactic acid bacteria against food mutagens: heterocyclic amines. J Dairy Res. 2002;69(2):335-41.

43. Li S-C, Hsu W-F, Chang J-S, Shih C-K. Combination of Lactobacillus acidophilus and Bifidobacterium animalis subsp. lactis shows a stronger anti-inflammatory effect than individual strains in $\mathrm{HT}-29$ cells. Nutrients. 2019;11(5):969.

44. Miller LE, Lehtoranta L, Lehtinen MJ. The effect of Bifidobacterium animalis ssp. lactis HN019 on cellular immune function in healthy elderly subjects: systematic review and meta-analysis. Nutrients. 2017;9(3):191.

45. Yu H-G, Zhong X, Yang Y-N, Luo H-S, Yu J-P, Meier JJ, Schrader H, Bastian A, Schmidt WE, Schmitz F. Increased expression of nuclear factor-KB/RelA is correlated with tumor angiogenesis in human colorectal cancer. Int J Colorectal Dis. 2004;19(1):18-22.

46. Kim SW, Kim HM, Yang KM, Kim S-A, Kim S-K, An MJ, Park JJ, Lee SK, Kim TI, Kim WH. Bifidobacterium lactis inhibits NF-KB in intestinal epithelial cells and prevents acute colitis and colitis-associated colon cancer in mice. Inflamm Bowel Dis. 2010;16(9):1514-25.

47. Fahmy CA, Gamal-Eldeen AM, El-Hussieny EA, Raafat BM, Mehanna NS, Talaat RM, Shaaban MT. Bifidobacterium longum suppresses murine colorectal cancer through the modulation of oncomirs and tumor suppressor mirnas. Nutr Cancer. 2019;71(4):688-700.

48. Kucharczak J, Simmons MJ, Fan Y, Gélinas C. To be, or not to be: NF-kap$\mathrm{paB}$ is the answer-role of Rel/NF-kappaB in the regulation of apoptosis. Oncogene. 2003;22(56):8961-82.

\section{Publisher's Note}

Springer Nature remains neutral with regard to jurisdictional claims in published maps and institutional affiliations.

Ready to submit your research? Choose BMC and benefit from:

- fast, convenient online submission

- thorough peer review by experienced researchers in your field

- rapid publication on acceptance

- support for research data, including large and complex data types

- gold Open Access which fosters wider collaboration and increased citations

- maximum visibility for your research: over 100M website views per year

At BMC, research is always in progress.

Learn more biomedcentral.com/submissions 